\title{
Budget Impact Analysis of Afatinib for First-Line Treatment of Patients with Metastatic Non-Small Cell Lung Cancer with Epidermal Growth Factor Receptor Exon 19 Deletions or Exon 21 Substitution Mutations in a U.S. Health Plan
}

\author{
Jonathan Graham, BS; Stephanie Earnshaw, PhD; Kate Burslem, MSc; and Jonathan Lim, MSc, MEng
}

\begin{abstract}
BACKGROUND: Afatinib is 1 of 3 tyrosine kinase inhibitors approved in the United States for the first-line treatment of patients with metastatic nonsmall cell lung cancer (NSCLC) whose tumors have epidermal growth factor receptor (EGFR) exon 19 deletions (del19) or exon 21 (L858R) substitution mutations. In clinical trials, afatinib has demonstrated improvement in progression-free survival versus standard chemotherapy and gefitinib.

OBJECTIVE: To analyze the impact of increases in afatinib treatment share on the cost and health outcomes in a commercial health plan in the United States.

METHODS: A decision model was developed to evaluate the budget impact of increases in afatinib share for the first-line treatment of patients with metastatic NSCLC with EGFR del19 or L858R substitution mutations over a 5-year time horizon. The model compared the total annual costs for a health plan with 1 million covered lives in a scenario in which afatinib share increased 5 percentage points annually to one in which all treatment shares remained constant over time. The number of patients eligible for treatment was estimated using published incidence data. Therapies included in the model were afatinib, erlotinib, gefitinib, and the chemotherapy doublet, pemetrexed in combination with cisplatin. The mean time spent by patients in progression-free and progressive disease states was based on survival data from clinical trials and a network meta-analysis. Therapyrelated costs included monthly drug acquisition and administration costs and costs of managing adverse reactions. Disease management costs were also assessed in the model. Scenario analyses were performed to assess alternative scenarios of afatinib treatment share. Additionally, a one-way sensitivity analysis was performed to test the robustness of the model, given parameter uncertainty.
\end{abstract}

RESULTS: Using the base-case parameter assumptions and a 5-percentage-point annual increase in afatinib treatment share, we estimated the total budget increases in years 1 through 5 to be $\$ 1,606, \$ 65,542$, $\$ 140,564, \$ 209,272$, and $\$ 303,368$, respectively. These budget increases translated to per-member-per-month increases ranging from $\$ 0.00$ to $\$ 0.03$ in years 1 to 5 . The increase in afatinib use resulted in the proportion of the treated population (134 patients treated over 5 years) remaining in progression-free disease increasing from $23.7 \%$ to $26.2 \%$ at the end of year 5 , versus if afatinib treatment share had stayed constant.

CONCLUSIONS: Increasing the treatment share of afatinib in a health plan for the first-line treatment of NSCLC with EGFR del19 or L858R mutations was estimated to increase the proportion of treated patients remaining in progression-free disease, while having small budget impact to the health plan.

J Manag Care Spec Pharm. 2018;24(6):544-53

Copyright $\odot 2018$, Academy of Managed Care Pharmacy. All rights reserved.

\section{What is already known about this subject}

All 3 tyrosine kinase inhibitors have demonstrated increased progression-free survival compared with standard platinumbased chemotherapy.

Afatinib has shown improvement in progression-free survival compared with gefitinib.

\section{What this study adds}

This study estimates the budget impact of a 5-percentage-point annual growth in treatment share of afatinib, as well as the projected clinical outcomes from a health plan perspective.

Base-case findings show that a 5-percentage-point annual growth in afatinib share will result in an annual budget impact from $\$ 0.0001$ per-member-per-month cost in year 1 to $\$ 0.0253$ permember-per-month cost in year 5 .

Over a 5-year period, increases in afatinib use in a health plan population would increase the proportion of the treated population that is progression free (from $23.7 \%$ to $26.2 \%$ ).

W ith an estimated 222,500 newly diagnosed cases of lung cancer and 155,870 deaths expected in 2017, lung cancer represents the second most common cancer and the leading cause of cancer death in the United States. Non-small cell lung cancer (NSCLC) is the most common type of lung cancer, accounting for approximately 80\%-85\% of cases. Prognosis and treatment approaches for NSCLC depend on several factors, including tumor size, tumor characteristics, metastases and vascular invasion, and pulmonary symptoms. Most cases of lung cancer are diagnosed as being in advanced stages. ${ }^{1}$

NSCLC harboring activating epidermal growth factor receptor (EGFR) mutations is highly responsive to EGFR-targeting tyrosine kinase inhibitors (TKIs), and these mutations exist in approximately 10\%-15\% of Caucasian patients with NSCLC, and up to $50 \%$ of Asian patients with NSCLC. ${ }^{2}$ The 2 most common types of EGFR mutations, exon 19 deletions (del19) or exon 21 (L858R) substitution mutations, account for $90 \%$ of all EGFR mutations. ${ }^{3}$ 
Budget Impact Analysis of Afatinib for First-Line Treatment of Patients with Metastatic Non-Small Cell Lung Cancer with Epidermal Growth Factor Receptor Exon 19 Deletions or Exon 21 Substitution Mutations in a U.S. Health Plan

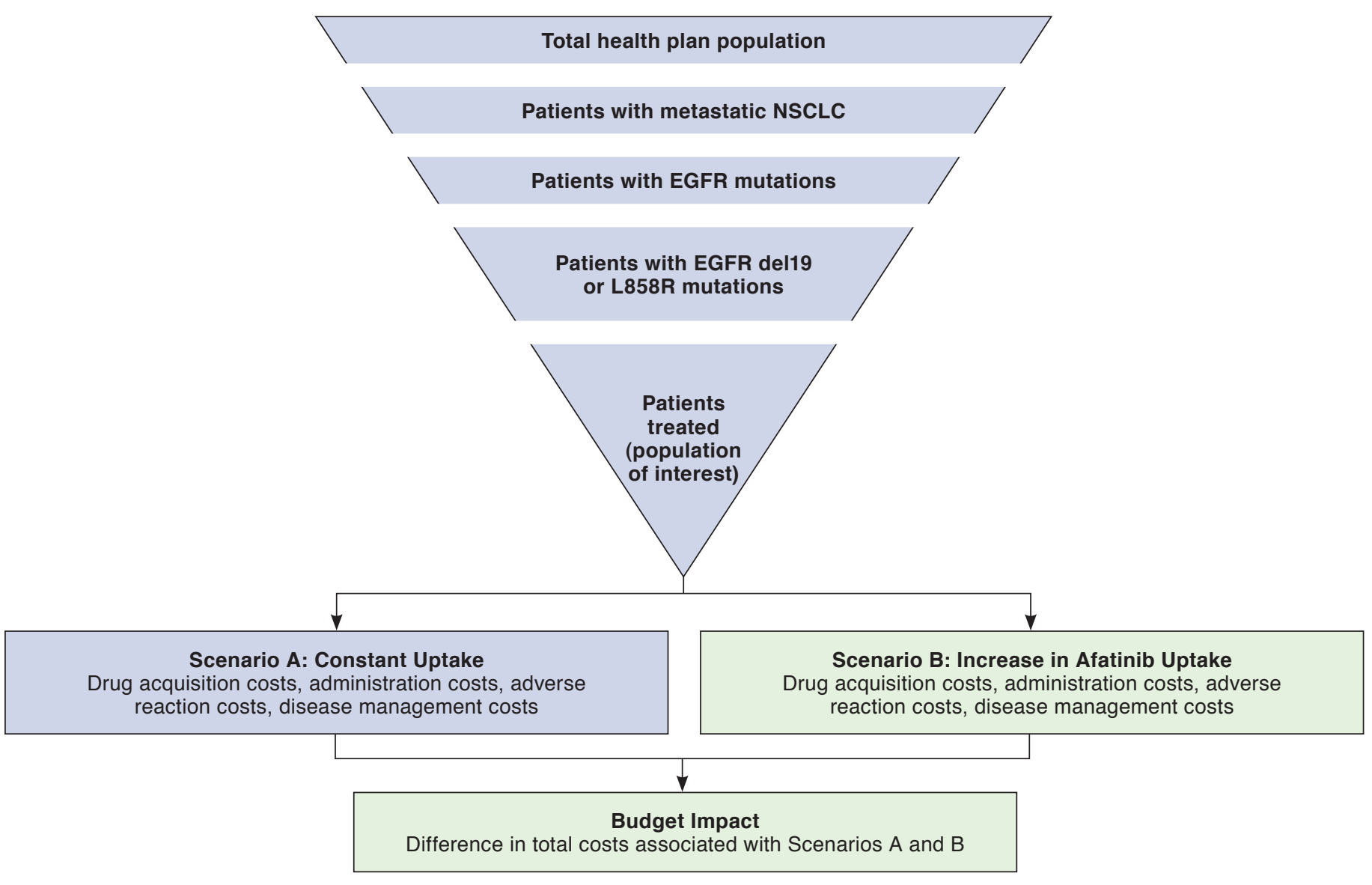

EGFR=epidermal growth factor receptor; NSCLC = non-small cell lung cancer.

Currently, there are 3 EGFR TKIs that have been approved in the United States for the first-line treatment of metastatic NSCLC with EGFR del19 and L858R mutations. Erlotinib and gefitinib are first-generation EGFR TKIs that reversibly bind to and inhibit the kinase activity of EGFR. Afatinib is a second-generation EGFR TKI that irreversibly binds to EGFR, human EGFR 2, and ErbB4 receptors, resulting in down regulation of ErbB signaling preventing the overgrowth of the cell. The National Comprehensive Cancer Network (NCCN) recommends any of the 3 EGFR TKIs as first-line therapy for metastatic NSCLC with EGFR del19 and L858R mutations. ${ }^{4}$ While all 3 EGFR TKIs have demonstrated improvements in progression-free survival (PFS) versus standard chemotherapy in the first-line treatment of EGFR mutation-positive NSCLC, afatinib was the only TKI to demonstrate improvement in overall survival (OS) versus standard chemotherapy in NSCLC patients with EGFR del19 mutations. ${ }^{5}$ Furthermore, afatinib was shown to improve PFS in patients with del19 or L858R mutations compared with gefitinib in a recently published phase $2 \mathrm{~b}$ trial. ${ }^{6}$

A budget impact model was developed to evaluate the costs and outcomes associated with an increased use of afatinib in a U.S. health plan population as the first-line treatment of NSCLC with EGFR del19 or L858R mutations.

\section{Methods}

\section{Model Structure}

A decision model was constructed to estimate the impact on cost and health outcomes that a potential increase in afatinib treatment shares would have on a U.S. commercial health plan over a 5-year period. The model compared 2 scenarios: 1 in which treatment shares remained the same each year (Scenario A), and the other in which afatinib treatment shares increased annually (Scenario B; Figure 1). The model estimated costs and outcomes for each scenario in a hypothetical plan of 1 million individuals. 


\section{TABLE 1 Model Parameter Values}

\begin{tabular}{|c|c|c|c|}
\hline Input Parameter & Base Case ${ }^{a}$ & $\begin{array}{c}\text { Plausible Range } \\
\text { Tested in } \\
\text { Sensitivity } \\
\text { Analysis }\end{array}$ & Reference \\
\hline \multicolumn{4}{|l|}{ Population } \\
\hline $\begin{array}{l}\text { Number of enrollees in } \\
\text { health plan }\end{array}$ & $1,000,000$ & N/A & Assumption \\
\hline $\begin{array}{l}\text { Percentage of health plan } \\
\text { patients } \geq 18 \text { years }\end{array}$ & 77.1 & N/A & 29,30 \\
\hline $\begin{array}{l}\text { Percentage diagnosed with } \\
\text { lung cancer annually, by age }\end{array}$ & 0.1 & N/A & 29,30 \\
\hline $\begin{array}{l}\text { Percentage of lung cancer } \\
\text { that is NSCLC }\end{array}$ & 74.8 & N/A & 29,30 \\
\hline $\begin{array}{l}\text { Percentage with NSCLC } \\
\text { patients who have metastatic } \\
\text { disease }\end{array}$ & 61.5 & N/A & 31 \\
\hline $\begin{array}{l}\text { Percentage tested for EGFR } \\
\text { mutation }\end{array}$ & 77.0 & N/A & 32 \\
\hline $\begin{array}{l}\text { Percentage testing positive } \\
\text { for EGFR mutation }\end{array}$ & 13.9 & N/A & 33 \\
\hline $\begin{array}{l}\text { Percentage with EGFR } \\
\text { mutation with del19 or } \\
\text { L858R mutation }\end{array}$ & 90.0 & N/A & 4 \\
\hline $\begin{array}{l}\text { Percentage of patients who } \\
\text { receive first-line therapy }\end{array}$ & 100.0 & N/A & Assumption \\
\hline \multicolumn{4}{|l|}{ Mean survival, months ${ }^{b}$} \\
\hline \multicolumn{4}{|l|}{ Progression-free survival } \\
\hline Afatinib & 19.82 & $15.42-25.16$ & 12 \\
\hline Erlotinib & 12.52 & $8.49-19.08$ & 14 \\
\hline Gefitinib & 13.71 & $10.32-17.19$ & 13 \\
\hline Pemetrexed/cisplatin & 9.30 & $7.08-12.33$ & 12 \\
\hline \multicolumn{4}{|l|}{ Overall survival } \\
\hline Afatinib & 46.26 & $36.94-56.15$ & \\
\hline Erlotinib & 41.89 & $31.83-54.79$ & 14 \\
\hline Gefitinib & 40.13 & $31.83-49.72$ & 6 \\
\hline Pemetrexed/cisplatin & 37.06 & $28.01-48.43$ & 5 \\
\hline
\end{tabular}

The model started with 1 million health plan members, from which the annual number of EGFR mutation-positive NSCLC patients newly eligible for treatment was estimated. The monthly number of eligible patients was then derived from this annual figure with the assumption that treatment was initiated by the same number of eligible patients each month. Eligible patients then entered the model at monthly intervals with progression-free disease and were treated with one of the modeled therapies.

The model included the following therapies for metastatic EGFR mutation-positive NSCLC: afatinib, erlotinib, gefitinib, and the platinum doublet chemotherapy combination of pemetrexed and cisplatin. The EGFR TKIs (oral tablets) were assumed to be taken daily until disease progression, while pemetrexed/cisplatin was assumed to be administered every 21 days for a maximum of 6 cycles. Dosing was based on recommended dose in the prescribing information..$^{7-11}$

\begin{tabular}{|c|c|c|c|}
\hline Input Parameter & Base Case ${ }^{a}$ & $\begin{array}{c}\text { Plausible Range } \\
\text { Tested in } \\
\text { Sensitivity } \\
\text { Analysis }\end{array}$ & Reference \\
\hline \multicolumn{4}{|c|}{ Adverse reaction frequency, $\%^{c}$} \\
\hline \multicolumn{4}{|c|}{ Afatinib } \\
\hline Anemia & 0.44 & $0.00-1.29$ & 12 \\
\hline Diarrhea & 14.41 & $9.87-18.95$ & \\
\hline Fatigue & 1.31 & $0.00-2.78$ & \\
\hline Leukopenia & 0.44 & $0.00-1.29$ & \\
\hline Neutropenia & 0.44 & $0.00-1.29$ & \\
\hline Paronychia & 11.35 & $7.25-15.45$ & \\
\hline Rash & 16.16 & $11.40-20.91$ & \\
\hline Stomatitis & 8.73 & $5.08-12.38$ & \\
\hline \multicolumn{4}{|l|}{ Erlotinib } \\
\hline Anemia & 1.19 & $0.00-3.50$ & 17 \\
\hline Diarrhea & 4.76 & $0.23-9.29$ & \\
\hline Dyspnea & 8.33 & $2.46-14.21$ & \\
\hline Fatigue & 5.95 & $0.92-10.98$ & \\
\hline Rash & 13.10 & $5.92-20.27$ & \\
\hline \multicolumn{4}{|l|}{ Gefitinib } \\
\hline Anemia & 2.17 & $1.00-3.34$ & 18 \\
\hline Diarrhea & 3.79 & $2.27-5.31$ & \\
\hline Leukopenia & 1.50 & $0.53-2.48$ & \\
\hline Neutropenia & 3.51 & $2.03-4.98$ & \\
\hline Paronychia & 0.33 & $0.00-0.79$ & \\
\hline Rash & 3.13 & $1.75-4.51$ & \\
\hline Stomatitis & 0.16 & $0.00-0.49$ & \\
\hline \multicolumn{4}{|c|}{ Pemetrexed/cisplatin } \\
\hline Anemia & 6.31 & $1.80-10.81$ & 12 \\
\hline Fatigue & 12.61 & $6.46-18.76$ & \\
\hline Leukopenia & 8.11 & $3.05-13.16$ & \\
\hline Neutropenia & 18.02 & $10.90-25.14$ & \\
\hline Stomatitis & 0.90 & $0.00-2.65$ & \\
\hline
\end{tabular}

Based on the treatment share for each scenario and the eligible patient population, the total costs associated with each scenario were estimated. Annual costs over a 5-year period were then compared between the 2 scenarios to obtain the budget impact on the health plan with adopting an annual increase in afatinib use. Results are reported in total annual and permember-per-month (PMPM) costs. The model also estimated the health outcome impact by calculating the proportions of the population in the 3 health statuses (progression-free disease, progressive disease, death) for each scenario.

\section{Population}

The eligible population included individuals with metastatic NSCLC whose tumors have EGFR del19 or L858R mutations initiating first-line treatment. The age of the population considered was $\geq 18$ years. 
TABLE 1 Model Parameter Values (continued)

\begin{tabular}{|c|c|c|c|c|c|c|c|c|}
\hline Input Parameter & \multicolumn{2}{|c|}{ Base Case $^{\mathrm{a}}$} & $\begin{array}{c}\text { Plausible Range } \\
\text { Tested in } \\
\text { Sensitivity } \\
\text { Analysis } \\
\end{array}$ & Reference & Input Parameter & Base Case ${ }^{\mathrm{a}}$ & \begin{tabular}{|} 
Plausible Range \\
Tested in \\
Sensitivity \\
Analysis
\end{tabular} & Reference \\
\hline \multicolumn{5}{|c|}{ Adverse reaction, 1-time costs to treat, $\$^{\mathrm{d}, \mathrm{e}}$} & \multicolumn{4}{|l|}{ Drug acquisition costs, $\$$} \\
\hline Anemia & $10,130.63$ & \multicolumn{2}{|c|}{$8,104.50-12,156.76$} & 19,23 & Afatinib (monthly) & $7,550.71$ & N/A & 15 \\
\hline Diarrhea & $7,361.30$ & \multicolumn{2}{|c|}{$5,889.04-8,833.56$} & & Erlotinib (monthly) & $7,825.37$ & N/A & 15 \\
\hline Dyspnea & $7,053.29$ & \multicolumn{2}{|c|}{$5,642.63-8,463.95$} & & Gefitinib (monthly) & $7,597.80$ & N/A & 15 \\
\hline Fatigue & $7,160.73$ & \multicolumn{2}{|c|}{$5,728.59-8,592.88$} & & Pemetrexed/cisplatin per cycle ${ }^{f}$ & $5,911.72$ & N/A & $7-8,15$ \\
\hline Leukopenia & $7,265.55$ & \multicolumn{2}{|c|}{$5,812.44-8,718.66$} & & $\begin{array}{l}\text { Pemetrexed/cisplatin } \\
\text { administration costs per cycle }{ }^{\mathrm{f}, \mathrm{h}}\end{array}$ & 715.86 & N/A & \\
\hline Neutropenia & $11,999.29$ & \multicolumn{2}{|c|}{$9,599.43-14,399.15$} & & $\begin{array}{l}\text { Other monthly progression-free } \\
\text { disease costs, } \$ \mathrm{~h}, \mathrm{i}\end{array}$ & $1,971.79$ & $1,027.33-2,927.15$ & $\begin{array}{c}16,17,20 \\
21,23\end{array}$ \\
\hline Paronychia & $5,226.28$ & \multicolumn{2}{|c|}{$4,181.02-6,271.54$} & & \multicolumn{4}{|c|}{ Monthly progressive disease costs, $\$$} \\
\hline Rash & $5,110.00$ & \multicolumn{2}{|c|}{$4,088.00-6,132.00$} & & Continuing care & 491.13 & $455.12-527.20$ & $22-23$ \\
\hline Stomatitis & $12,370.37$ & \multicolumn{2}{|c|}{$9,896.30-14,844.45$} & & End of life & $6,540.96$ & $6,428.87-6,653.13$ & $22-23$ \\
\hline $\begin{array}{l}\text { aEach number pres } \\
\text { exactly to their par } \\
\text { bDetails on derivat } \\
\text { cPlausible range tes } \\
\text { dInternational Clas } \\
\text { (288.5), neutropen } \\
\text { ePlausible range tes } \\
\text { fDerived from comb } \\
\text { gDerived from comb } \\
\text { hThe Medicare-base } \\
\text { See Appendix B }\end{array}$ & $\begin{array}{l}\text { as been round } \\
\text { nean survival } \\
\text { ensitivity ana } \\
\text { on of Diseases } \\
\text { O3), paronych } \\
\text { ensitivity ana } \\
\text { sing informat } \\
\text { idministration } \\
\text { from the RBR } \\
\text { in online art }\end{array}$ & $\begin{array}{l}\text { to the } \\
\text { imates } \\
\text { is basec } \\
\text { Ninth R, } \\
\text { (681.0 } \\
\text { is calcu } \\
\text { afrom } t \\
\text { format } \\
\text { Swere } \\
\text { e) for de }\end{array}$ & $\begin{array}{l}\text { lecimal place preser } \\
\text { are available from } t \\
\text { lon } 95 \% \text { confidence } \\
\text { vision, codes used } \\
2,681.11 \text { ), rash ( } 78 \\
\text { lated as } \pm 20 \% \text { of b } \\
\text { he prescribing inforn } \\
\text { on from the prescri } \\
\text { idjusted upward by } \\
\text { tails on derivation }\end{array}$ & $\begin{array}{l}\text { ited. Totals ar } \\
\text { he authors on } \\
\text { interval from } \\
\text { vere as follow. } \\
2.1 \text {, and stom } \\
\text { ase-case value } \\
\text { lation, RED B } \\
\text { bing informati } \\
20 \% \text { to estima } \\
\text { f cost estimat }\end{array}$ & $\begin{array}{l}\text { Dunded after using unrounded numbers } \\
\text { uest. } \\
\text { urce data. } \\
\text { nemia (280-295), diarrhea (787.91), } \\
\text { tis (528). } \\
\text { K Online's cost per milligram of drug, } \\
\text { and unit costs from the Essential RBRV } \\
\text { commercial health plan costs. }\end{array}$ & $\begin{array}{l}\text { dyspnea }(786 \\
\text { and an assum } \\
\text { RS. }{ }^{16}\end{array}$ & $\begin{array}{l}\text {.09), fatigue (780.79), } \\
\text { ned body surface area of }\end{array}$ & $\begin{array}{l}\text {, leukopenia } \\
\text { of } 1.83 \mathrm{~m}^{2} \text {. }\end{array}$ \\
\hline
\end{tabular}

The eligible patient population was estimated from the total health plan population using the information presented in Table 1.

\section{Treatment Shares}

In Scenario A, it was assumed that $65 \%$ of the eligible patient population was treated with erlotinib, $25 \%$ with afatinib, 5\% with gefitinib, and the remaining $5 \%$ with pemetrexed/cisplatin. These hypothetical treatment shares were assumed to remain constant over the 5-year time horizon. For Scenario B, the treatment share of afatinib was assumed to increase 5 percentage points each year, with this treatment share taken proportionately from the other therapies based on the treatment distribution stated above. Shares are applied to patients initiating first-line treatment only, as patients do not switch first-line treatments after starting. Treatment shares for both scenarios are presented in Appendix A (available in online article).

\section{Clinical Effect}

Patients enter the model with progression-free disease and advance to progressive disease and death based on mean PFS and OS, respectively. Time in progression-free disease for individuals on each therapy was estimated using the mean PFS.
The time in progressive disease was estimated using the difference of mean OS and the mean time in progression-free disease.

To calculate the mean survival for afatinib, the area under the curve (AUC) using the best-fitting parametric survival models for both PFS and OS was calculated based on empirical data from the LUX-Lung 3 clinical trial. Weibull, Gompertz, log-logistic, and log-normal survival models were fit to the data. The log-logistic was found to be the best fit to the PFS data while the Weibull was the best fit for OS.

The survival curves for erlotinib, gefitinib, and pemetrexed/ cisplatin were estimated based on hazard ratios (HRs) that were applied to the hazard function for each afatinib parametric model. Mean survival for these therapies was also estimated by calculating the AUC of each therapy's estimated survival curves.

The HRs for afatinib versus pemetrexed/cisplatin were obtained from LUX-Lung 3. The PFS HR was 0.47 (95\% confidence interval $[\mathrm{CI}]=0.34-0.65$ ) and the OS $\mathrm{HR}$ was 0.78 (95\% CI $=0.58-1.06$ ). ${ }^{5,12}$ The HRs for afatinib versus gefitinib were obtained from LUX-Lung 7. The PFS HR was 0.73 (95\% $\mathrm{CI}=0.57-0.95)$ and the OS HR was $0.86(95 \% \mathrm{CI}=0.66-1.12){ }^{6,13}$ 
The HRs for afatinib versus erlotinib were obtained from an update (data on file, Boehringer Ingelheim, NMA report: update of the existing network meta-analysis of clinical evidence on afatinib in first-line EGFR mutation-positive NSCLC, October 20, 2016) to the previously published network metaanalysis (NMA) of trials for the treatment of EGFR mutationpositive NSCLC. ${ }^{14}$ The NMA was updated to include newer studies, including the results of LUX-Lung 7. The NMA used results from an independent reviewer assessment and analyzed them based on Bayesian methods. For PFS, 10 studies were used in the network and for OS, 11 studies were used. Table 1 presents the survival estimates for each therapy.

\section{Costs}

The model was built from a payer perspective and did not consider indirect costs; only direct medical and drug costs were considered.

Drug acquisition costs were based on wholesale acquisition costs obtained from the Micromedex Red Book online. ${ }^{15}$ The chemotherapy administration cost was calculated from the resources used as described in the prescribing information and the unit costs for these resources, which were taken from the Essential Resource-Based Relative Value Scale (RBRVS). ${ }^{16}$

One-time costs to manage adverse reactions were applied to those who experienced therapy-related adverse reactions. The model considers only grade 3 or 4 adverse reactions that occur in at least $5 \%$ of patients in the clinical trials for each respective therapy, as these are the adverse reactions likely to result in a change in resource use. ${ }^{12,17,18}$ As grade 3 and 4 adverse reactions can be associated with hospitalization, these costs were based on inpatient treatment costs obtained from the Healthcare Cost and Utilization Project. ${ }^{19}$ Adverse reaction management costs were applied to adverse reactions that occur until progression. Although adverse reactions may occur over the course of time in which the TKIs and chemotherapy are administered, for simplicity, they were assumed to be incurred in the first month of therapy.

In addition to therapy-related costs associated with progression-free disease, it was acknowledged that patients also incur other medical costs associated with the management of their disease. These may include outpatient visits, outpatient resources (computed tomography scans, magnetic resonance imaging, ultrasounds, x-rays, radiotherapy, respiratory surgical procedures), emergency department visits, and unplanned hospitalizations. The resource-use information for NSCLC patients with progression-free disease was collected from the LUX-Lung 3 trial. The monthly resource use was then multiplied by the unit costs associated with each health care resource to derive the monthly disease management costs..$^{16,19-21}$ These costs were applied each month a patient was experiencing progressionfree disease. See Appendix B for more detail.
Progressive disease costs were made up of monthly continuing-care costs that were applied at each month between progression and the last year of life, and end-of-life costs that were applied in each month during the last 12 months of life. These costs were obtained from Yabroff et al. (2008). ${ }^{22}$ See Table 1 for a summary of costs used in the model.

All costs were inflated to 2017 U.S. dollars using the medical care component of the Consumer Price Index. ${ }^{23}$

\section{Model Outputs}

The budget impact analysis was conducted over 5 years, costs were presented undiscounted, and results were presented disaggregated over time, as recommended by the International Society for Pharmacoeconomics and Outcome Research's Task Force on Good Research Practices. ${ }^{24}$

The budget impact analysis estimated (a) progression-free disease costs that include drug acquisition and administration costs, adverse reaction costs, and other disease management costs, and (b) progressive disease costs, which include continuing-care costs and end-of-life costs. Costs were reported as annual total costs for the population and PMPM.

In addition to cost estimates, the analysis provided the distribution of patients in the treated population who were in progression-free disease, in progressive disease, or had died for each budget year.

Scenario analyses were performed to explore alternate treatment share assumptions. In these scenario analyses, afatinib treatment share was assumed to increase annually by 2.5 percentage points (Scenario B-1: Less Aggressive Uptake of Afatinib) and 10 percentage points (Scenario B-2: More Aggressive Uptake of Afatinib). Another scenario was examined in which the 5-percentage-point annual increase in afatinib treatment share was assumed to come solely from a reduction in erlotinib treatment share, instead of proportionately across the other therapy options (Scenario B-3: Shares from Erlotinib). The specific treatment shares are provided in Appendix A.

The robustness of model assumptions and uncertainty around specific parameters were tested in one-way sensitivity analyses. The effect of varying each parameter on the difference in total annual cost in year 5 was examined. The one-way sensitivity analyses results were displayed on tornado diagrams, ranked from the most sensitive to least sensitive parameters.

\section{Results}

\section{Base-Case Analysis}

Out of a 1-million-member health plan, it was estimated that there would be 27 newly diagnosed patients with metastatic NSCLC whose tumors have EGFR del19 or L858R mutations initiating first-line therapy each year (Table 2).

Comparing Scenario A (Constant Uptake) and Scenario B (Increase in Afatinib Uptake), the model estimated that total 
Budget Impact Analysis of Afatinib for First-Line Treatment of Patients with Metastatic Non-Small Cell Lung Cancer with Epidermal Growth Factor Receptor Exon 19 Deletions or Exon 21 Substitution Mutations in a U.S. Health Plan

\section{TABLE 2 Base-Case Results}

\begin{tabular}{|c|c|c|c|c|c|}
\hline Result $^{\mathrm{a}}$ & Year 1 & Year 2 & Year 3 & Year 4 & Year 5 \\
\hline $\begin{array}{l}\text { Total number of patients who have been } \\
\text { treated by the end of each year }\end{array}$ & 27 & 54 & 81 & 107 & 134 \\
\hline \multicolumn{6}{|l|}{ Scenario A: Constant Uptake } \\
\hline Progression-free disease costs, $\$$ & $1,739,910$ & $3,589,723$ & $3,732,802$ & $3,732,802$ & $3,732,802$ \\
\hline Drug acquisition and administration costs & $1,326,381$ & $2,795,273$ & $2,908,726$ & $2,908,726$ & $2,908,726$ \\
\hline Adverse reaction costs & 70,581 & 70,581 & 70,581 & 70,581 & 70,581 \\
\hline Other disease management costs & 342,947 & 723,868 & 753,495 & 753,495 & 753,495 \\
\hline Progressive disease costs, $\$$ & 340 & 64,487 & 488,233 & $2,010,634$ & $2,327,416$ \\
\hline Continuing-care costs & 340 & 64,487 & 194,832 & 218,883 & 218,883 \\
\hline End-of-life costs & 0 & 0 & 293,401 & $1,791,752$ & $2,108,533$ \\
\hline Total costs, $\$$ & $1,740,249$ & $3,654,209$ & $4,221,035$ & $5,743,437$ & $6,060,218$ \\
\hline \multicolumn{6}{|l|}{ Population distribution at end of year, $\mathrm{n}(\%)$} \\
\hline Progression free & $26.5 \quad(98.7)$ & $31.8 \quad(59.3)$ & $31.8 \quad(39.5)$ & $31.8 \quad(29.6)$ & $31.8 \quad(23.7)$ \\
\hline Progressive & $0.3 \quad(1.3)$ & $21.9 \quad(40.7)$ & $48.7 \quad(60.5)$ & $63.6 \quad(59.2)$ & $63.6 \quad(47.3)$ \\
\hline Death & $0.0 \quad(0.0)$ & $0.0 \quad(0.0)$ & $0.0 \quad(0.0)$ & $12.0 \quad(11.2)$ & $38.9 \quad(28.9)$ \\
\hline \multicolumn{6}{|l|}{ Scenario B: Increase in Afatinib Uptake } \\
\hline Progression-free disease costs, $\$$ & $1,741,538$ & $3,658,777$ & $3,897,695$ & $3,993,533$ & $4,089,372$ \\
\hline Drug acquisition and administration costs & $1,325,851$ & $2,846,245$ & $3,033,730$ & $3,107,762$ & $3,181,794$ \\
\hline Adverse reaction costs & 72,650 & 74,718 & 76,786 & 78,855 & 80,923 \\
\hline Other disease management costs & 343,037 & 737,814 & 787,178 & 806,917 & 826,656 \\
\hline Progressive disease costs, $\$$ & 317 & 60,975 & 463,904 & $1,959,175$ & $2,274,214$ \\
\hline Continuing-care costs & 317 & 60,975 & 187,651 & 209,960 & 208,218 \\
\hline End-of-life costs & 0 & 0 & 276,253 & $1,749,215$ & $2,065,996$ \\
\hline Total costs, $\$$ & $1,741,855$ & $3,719,751$ & $4,361,599$ & $5,952,708$ & $6,363,586$ \\
\hline \multicolumn{6}{|l|}{ Population distribution at end of year, n (\%) } \\
\hline Progression free & $26.5 \quad(98.8)$ & $32.7 \quad(60.9)$ & $33.5 \quad(41.6)$ & $34.4 \quad(32.0)$ & $35.2 \quad(26.2)$ \\
\hline Progressive & $0.3 \quad(1.2)$ & $21.0 \quad(39.1)$ & $47.1 \quad(58.4)$ & $61.6 \quad(57.3)$ & $61.3 \quad(45.7)$ \\
\hline Death & $(0.0)$ & $0.0 \quad(0.0)$ & $0.0 \quad(0.0)$ & $11.5 \quad(10.7)$ & $37.8 \quad(28.1)$ \\
\hline \multicolumn{6}{|l|}{ Incremental (absolute difference) } \\
\hline Progression-free disease costs, $\$$ & 1,628 & 69,054 & 164,893 & 260,731 & 356,570 \\
\hline Drug acquisition and administration costs & -530 & 50,972 & 125,004 & 199,036 & 273,067 \\
\hline Adverse reaction costs & 2,068 & 4,137 & 6,205 & 8,273 & 10,342 \\
\hline Other disease management costs & 90 & 13,945 & 33,684 & 53,422 & 73,161 \\
\hline Progressive disease costs, $\$$ & -23 & $-3,512$ & $-24,329$ & $-51,460$ & $-53,201$ \\
\hline Continuing-care costs & -23 & $-3,512$ & $-7,181$ & $-8,923$ & $-10,665$ \\
\hline End-of-life costs & 0 & 0 & $-17,148$ & $-42,537$ & $-42,537$ \\
\hline Total costs, $\$$ & 1,606 & 65,542 & 140,564 & 209,272 & 303,368 \\
\hline Budget impact per member per month, $\$$ & 0.0001 & 0.0055 & 0.0117 & 0.0174 & 0.0253 \\
\hline
\end{tabular}

annual costs would increase by $\$ 1,606, \$ 65,542, \$ 140,564$, $\$ 209,272$, and $\$ 303,368$ in years 1 through 5 , respectively, within a health plan (Table 3). These increases were driven by the estimated longer period that afatinib patients experience progression-free disease compared with patients on other therapies. At the end of year 5, 26.2\% of the treated population in Scenario B was in the progression-free disease state versus only $23.7 \%$ in Scenario A. Additionally, at the end of year 5, $71.9 \%$ of the treated population in Scenario B was alive compared with only $71.1 \%$ in Scenario A.
Increases in total costs resulted in small PMPM budget increases. These were $\$ 0.0001, \$ 0.0055, \$ 0.0117, \$ 0.0174$, and $\$ 0.0253$ in years 1 through 5 , respectively.

\section{Scenario Analysis}

Results of the scenario analysis are presented in Table 3. Reducing afatinib's annual increase in uptake to 2.5 percentage points reduced the cost impact, with the PMPM estimated to be $\$ 0.0001$ in year 1 and $\$ 0.0126$ in year 5 . However, with a smaller increase in afatinib, treatment share also resulted in a 
Budget Impact Analysis of Afatinib for First-Line Treatment of Patients with Metastatic Non-Small Cell Lung Cancer with Epidermal Growth Factor Receptor Exon 19 Deletions or Exon 21 Substitution Mutations in a U.S. Health Plan

\section{TABLE 3 Scenario Analysis (Incremental Costs)}

\begin{tabular}{|c|c|c|c|c|c|}
\hline Result $^{\mathrm{a}}$ & Year 1 & Year 2 & Year 3 & Year 4 & Year 5 \\
\hline \multicolumn{6}{|l|}{ Scenario B: Increase in Afatinib Uptake } \\
\hline Incremental total costs, $\$$ & 1,606 & 65,542 & 140,564 & 209,272 & 303,368 \\
\hline Incremental cost per member per month, $\$$ & 0.0001 & 0.0055 & 0.0117 & 0.0174 & 0.0253 \\
\hline \multicolumn{6}{|c|}{ Population distribution at end of year for projected afatinib scenario, $\mathrm{n}(\%)$} \\
\hline Progression free & $26.5(98.8)$ & $32.7 \quad(60.9)$ & $33.5 \quad(41.6)$ & $34.4 \quad(32.0)$ & $35.2 \quad(26.2)$ \\
\hline Progressive & $0.3 \quad(1.2)$ & $21.0 \quad(39.1)$ & $47.1 \quad(58.4)$ & $61.6 \quad(57.3)$ & $(45.7)$ \\
\hline Death & $0.0 \quad(0.0)$ & $0.0 \quad(0.0)$ & $0.0 \quad(0.0)$ & $11.5 \quad(10.7)$ & $37.8 \quad(28.1)$ \\
\hline \multicolumn{6}{|c|}{ Scenario B-1: Less Aggressive Uptake of Afatinib } \\
\hline Incremental total costs, \$ & 803 & 32,771 & 70,282 & 104,636 & 151,684 \\
\hline Incremental cost per member per month, $\$$ & 0.0001 & 0.0027 & 0.0059 & 0.0087 & 0.0126 \\
\hline \multicolumn{6}{|c|}{ Population distribution at end of year for projected afatinib scenario, $\mathrm{n}(\%)$} \\
\hline Progression free & $26.5(98.8)$ & $32.3(60.1)$ & $32.7(40.6)$ & $33.1 \quad(30.8)$ & $33.5 \quad(25.0)$ \\
\hline Progressive & $0.3 \quad(1.2)$ & $21.5 \quad(39.9)$ & $47.9 \quad(59.4)$ & $62.6 \quad(58.3)$ & $62.5 \quad(46.5)$ \\
\hline Death & $0.0 \quad(0.0)$ & $0.0 \quad(0.0)$ & $0.0 \quad(0.0)$ & $11.7 \quad(10.9)$ & $38.3(28.5)$ \\
\hline \multicolumn{6}{|c|}{ Scenario B-2: More Aggressive Uptake of Afatinib } \\
\hline Incremental total costs, $\$$ & 3,212 & 131,084 & 281,128 & 418,543 & 606,737 \\
\hline Incremental cost per member per month, $\$$ & 0.0003 & 0.0109 & 0.0234 & 0.0349 & 0.0506 \\
\hline \multicolumn{6}{|c|}{ Population distribution at end of year for projected afatinib scenario, $\mathrm{n}(\%)$} \\
\hline Progression free & $26.6 \quad(98.9)$ & $33.6 \quad(62.5)$ & $35.2(43.7)$ & $36.9 \quad(34.3)$ & $(28.7)$ \\
\hline Progressive & $0.3 \quad(1.1)$ & $20.2 \quad(37.5)$ & $45.4(56.3)$ & $59.6 \quad(55.5)$ & $59.0 \quad(44.0)$ \\
\hline Death & $(0.0)$ & $0.0 \quad(0.0)$ & $0.0 \quad(0.0)$ & $10.9 \quad(10.2)$ & $(27.3)$ \\
\hline \multicolumn{6}{|l|}{ Scenario B-3: Shares from Erlotinib } \\
\hline Incremental total costs, \$ & -211 & 58,828 & 131,796 & 196,434 & 285,370 \\
\hline Incremental cost per member per month, $\$$ & 0.0000 & 0.0049 & 0.0110 & 0.0164 & 0.0238 \\
\hline \multicolumn{6}{|c|}{ Population distribution at end of year for projected afatinib scenario, $\mathrm{n}(\%)$} \\
\hline Progression free & $26.5 \quad(98.7)$ & $32.7(60.8)$ & $33.5 \quad(41.5)$ & $34.3(31.9)$ & $35.1 \quad(26.1)$ \\
\hline Progressive & $0.3 \quad(1.3)$ & $21.1 \quad(39.2)$ & $47.1 \quad(58.5)$ & $61.6 \quad(57.4)$ & $61.3 \quad(45.6)$ \\
\hline Death & $(0.0)$ & $0.0 \quad(0.0)$ & $0.0 \quad(0.0)$ & $11.5 \quad(10.7)$ & $37.9 \quad(28.2)$ \\
\hline
\end{tabular}

lower proportion of the population remaining progression free compared with the base-case analysis results for Scenario B.

Conversely, when afatinib shares were assumed to increase 10 percentage points annually, the budget impact was estimated to double from the base case, but this was also accompanied by a higher proportion of the treatment population experiencing progression-free disease.

In Scenario B-3 (Shares from Erlotinib), the impact on total costs declined because of a reduction of treatment share of erlotinib, which has the highest wholesale acquisition cost among the 3 EGFR TKIs. Incremental PMPM costs were $\$ 0.0000$ in year 1 and $\$ 0.0238$ in year 5 under this scenario.

\section{Sensitivity Analysis}

Figure 2 presents the effect of key parameters on the total annual cost impact seen in year 5. Specifically, the results were most sensitive to the mean survival times for patients receiving afatinib or erlotinib. Changes in the remaining tested parameters had little impact on the change in budget.

\section{Discussion}

A budget impact analysis was performed to estimate the impact of increased use of afatinib in a population of patients with metastatic NSCLC whose tumors have del19 or L858R mutations and who initiate first-line treatment. The results of the budget impact analysis indicated that increasing the treatment share of afatinib in the treated population had a small financial impact on a health plan's budget. Compared with Scenario A (Constant Uptake), Scenario B (Increase in Afatinib Uptake), in which afatinib treatment share increased by 5 percentage points annually, was estimated to result in PMPM budget increases from $\$ 0.0001$ in year 1 to $\$ 0.0253$ in year 5 . Annual incremental PMPM increases were driven by estimated increases in the mean PFS and OS of the population that occurred with the increase in afatinib use with a health plan. Additionally, the PMPM budget impact was small due to the small number of treated patients in the health plan population. Overall, a health plan may see increases in its drug spend and patient quality of life when more patients on a health plan take afatinib. Patients live longer and spend more time being progression free. 
Budget Impact Analysis of Afatinib for First-Line Treatment of Patients with Metastatic Non-Small Cell Lung Cancer with Epidermal Growth Factor Receptor Exon 19 Deletions or Exon 21 Substitution Mutations in a U.S. Health Plan

FIGURE 2 One-Way Sensitivity Analysis: Impact of Changes of Input Parameters on the Change in Total Annual Budget in Year 5 (10 Most Sensitive Parameters Presented)

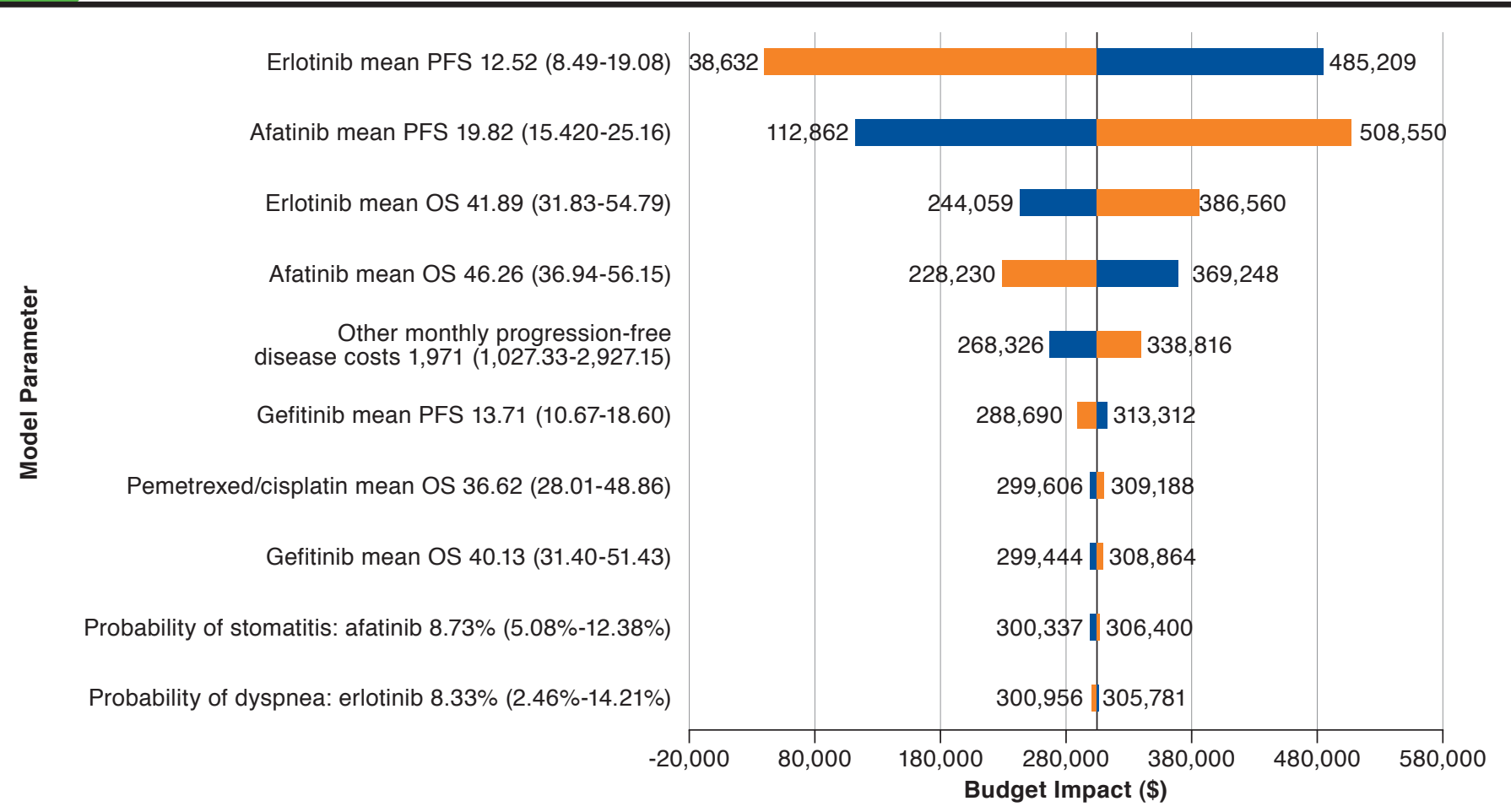

Annual budget impact associated with lower bound

Annual budget impact associated with upper bound

Note: Model parameter values are presented in the figure as mean (plausible range tested).

OS = overall survival; $P F S=$ progression-free survival .

To our knowledge, no prior U.S.-based analysis budget impact has included all 3 TKIs and focused on newly diagnosed patients with metastatic NSCLC whose tumors have EGFR del19 or L858R mutations initiating first-line therapy each year. Bajaj et al. (2014) analyzed the budget impact of erlotinib in first-line therapy. ${ }^{25}$ However, their focus was on the impact of increased EGFR testing, with patients testing positive receiving erlotinib and patients not testing or testing positive receiving chemotherapy. No other TKIs were considered in this analysis. Ramsey et al. (2006) estimated the impact of erlotinib use in second- and third-line therapy on the budget of a U.S. health plan. ${ }^{26}$ No other TKIs were considered in this analysis. Both studies looked only at changes in drug acquisition costs and did not consider other medical costs while progressionfree, as well as the impact on cost of extending overall survival. Thus, the impact on a payer's budget was not fully captured in these analyses.

\section{Limitations}

Because there are no clinical studies that have directly compared the use of afatinib, erlotinib, and gefitinib in first-line treatment of EGFR NSCLC, assumptions were made to estimate the differences in clinical effect. The clinical effect difference between afatinib and erlotinib was derived using an indirect comparison through a network meta-analysis. This is an approach commonly used in decision models when there is an absence of head-to-head data.

The clinical difference between afatinib and gefitinib was estimated using HRs from the LUX-Lung 7 trial and applying to the survival curves for the afatinib arm of LUX-Lung 3. While both LUX-Lung trials had similar inclusion and exclusion criteria, the trial populations are inherently different, which could affect the true survival of gefitinib relative to afatinib's survival. Sensitivity analysis showed that variation of the HRs within their plausible ranges had the most impact on the budget changes, as this affected time on therapy. 
Additionally, because the LUX-Lung 3 trial was a multinational trial, the resource-use data used to estimate the other medical costs associated with the management of progressionfree disease might not be applicable to a U.S. population. Data from LUX-Lung 3 resource use was used to keep the clinical effect commensurate with the care that was given during the trial. It is possible that resource use could differ in the United States. However, results of the sensitivity analysis showed that changes to other medical costs would likely have small impact on the budget changes.

Another possible limitation of the model is the assumption that costs due to adverse reactions occur only in the first month of treatment. Because information on timing and duration of the adverse reactions was not available from the clinical trial publications, it was assumed that adverse reactions occurred in the first month of treatment and lasted only for that month. This approach was consistently applied across the model for each therapy. This assumption is consistent with other cost studies for NSCLC based on the knowledge that most adverse reactions occur in the first month or cycle of therapy and last no longer than a month. ${ }^{27,28}$ Changes to this assumption would likely affect month-to-month budgeting but would likely have small impact on the annual budget in total.

Cost of progressive disease was from a study that based its analysis on data spanning 1999-2003. ${ }^{22}$ Given the years of the data, cost of progressive disease may be significantly different now. The costs were inflated to 2017 and were tested in the one-way sensitivity analysis. Reducing and increasing the cost had little effect on the change in budget, ranging from $\$ 302,585$ to $\$ 304,097$ in year 5 (base-case analysis was $\$ 303,368$ in year 5 ).

Compliance was assumed to be $100 \%$ for all treatments. However, this assumption may not reflect real-world practice. The model likely overestimated costs, as patients not taking therapy as directed would have an impact on the drug acquisition costs, but this would also affect the clinical effect.

\section{Conclusions}

Increasing the treatment share of afatinib in a health plan as the first-line treatment of NSCLC with EGFR del19 or L858R mutations is expected to increase the proportion of treated patients remaining in progression-free disease while having small financial impact on the health plan budget.

\section{Authors}

JONATHAN GRAHAM, BS, and STEPHANIE EARNSHAW, PhD, RTI Health Solutions, Research Triangle Park, North Carolina. KATE BURSLEM, MSc, and JONATHAN LIM, MSc, MEng, Boehringer Ingelheim Pharmaceuticals, Ridgefield, Connecticut.

AUTHOR CORRESPONDENCE: Jonathan Graham, BS, Director, Health Economics, RTI Health Solutions, 200 Park Offices Dr., Research Triangle Park, NC 27709. Tel.: 919.597.5138;

E-mail:jgraham@rti.org.

\section{DISCLOSURES}

Boehringer Ingelheim Pharmaceuticals funded this study research and was involved in all stages of study conduct, including the analysis of data, and also undertook all costs associated with the development and publication of this manuscript. Graham and Earnshaw are employees of RTI Health Solutions, an independent contract research organization that has received research funding for this and other studies from Boehringer Ingelheim Pharmaceuticals Lim and Burslem are employees of Boehringer Ingelheim Pharmaceuticals, which developed and produces afatinib, along with other pharmaceutical products.

\section{REFERENCES}

1. American Cancer Society. About non-small cell lung cancer. 2016. Available at: https://www.cancer.org/content/dam/CRC/PDF/Public/8703.00. pdf. Accessed April 14, 2018.

2. O'Kane GM, Bradbury PA, Feld R, et al. Uncommon EGFR mutations in advanced non-small cell lung cancer. Lung Cancer. 2017;109:137-44

3. Sharma SV, Bell DW, Settleman J, Haber DA. Epidermal growth factor receptor mutations in lung cancer. Nat Rev Cancer. 2007;7(3):169-81.

4. National Comprehensive Cancer Network. Non-small cell lung cancer. 2017. Available at: https://www.nccn.org/professionals/physician_gls/pdf/ nscl_blocks.pdf. Accessed April 14, 2018.

5. Yang JC, Wu YL, Schuler M, et al. Afatinib versus cisplatin-based chemotherapy for EGFR mutation-positive lung adenocarcinoma (LUX-Lung 3 and LUX-Lung 6): analysis of overall survival data from two randomised, phase 3 trials. Lancet Oncol. 2015;16(2):141-51.

6. Paz-Ares L, Tan EH, O'Byrne K, et al. Afatinib versus gefitinib in patients with EGFR mutation-positive advanced non-small-cell lung cancer: overall survival data from the phase IIb LUX-Lung 7 trial. Ann Oncol. 2017;28(2):270-77.

7. Alimta (permetrexed) for injection. Eli Lilly and Company. February 2015. Available at: http://uspl.lilly.com/alimta/alimta.html. Accessed April 14, 2018

8. Platinol (cisplatin) for injection. Bristol-Myers Squibb. May 2010. Available at: https://www.accessdata.fda.gov/drugsatfda_docs/ label/2010/018057s079lbl.pdf. Accessed April 14, 2017.

9. Gilotrif (afatinib) for oral use. Boehringer Ingelheim Pharmaceuticals. January 2018. Available at: http://docs.boehringer-ingelheim.com/ Prescribing\%20Information/PIs/Gilotrif/Gilotrif.pdf?DMW_FORMAT=pdf. Accessed April 14, 2018.

10. Tarceva (erlotinib) for oral use. Astellas Pharma U.S. and Genentech. October 2016. Available at: https://www.gene.com/download/pdf/tarceva_ prescribing.pdf. Accessed April 14, 2018.

11. Iressa (gefitinib) for oral use. AstraZeneca. July 2015. Available at: https://www.azpicentral.com/iressa/iressa.pdf\#page=1. Accessed April 14, 2018. 
12. Sequist LV, Yang JC, Yamamoto N, et al. Phase III study of afatinib or cisplatin plus pemetrexed in patients with metastatic lung adenocarcinoma with EGFR mutations. J Clin Oncol. 2013;31(27):3327-34.

13. Park K, Tan EH, O’Byrne K, et al. Afatinib versus gefitinib as first-line treatment of patients with EGFR mutation-positive non-small-cell lung cancer (LUX-Lung 7): a phase 2B, open-label, randomised controlled trial. Lancet Oncol. 2016;17(5):577-89.

14. Popat S, Mok T, Yang JC, et al. Afatinib in the treatment of EGFR mutation-positive NSCLC-a network meta-analysis. Lung Cancer. 2014;85(2):230-38.

15. Truven Health Analytics. RED BOOK Online. Accessed through Micromedex 2.0. 2015. Available at: http://www.micromedexsolutions.com/. Accessed April 29, 2018.

16. Optum360. The Essential RBRVS: a comprehensive listing of RBRVS values for CPT and HCPCS codes. Salt Lake City, UT: Ingenix; 2017.

17. Rosell R, Carcereny E, Gervais R, et al. Erlotinib versus standard chemotherapy as first-line treatment for European patients with advanced EGFR mutation-positive non-small-cell lung cancer (EURTAC): a multicentre, open-label, randomised phase 3 trial. Lancet Oncol. 2012;13(3):239-46.

18. Mok TS, Wu Y, Thongprasert S, et. al. Gefitinib or carboplatin-paclitaxel in pulmonary adenocarcinoma. N Engl J Med. 2009;361(10):948-57.

19. HCUPnet. Healthcare Cost and Utilization Project. 2014. Available at: http://hcupnet.ahrq.gov/. Accessed April 14, 2018.

20. Agency for Healthcare Research and Quality. Medical expenditure panel survey. 2014. Available at: http://meps.ahrq.gov. Accessed April 14, 2018

21. Candrilli S, Mauskopf J. How much does a hospital day cost? Poster presented at: 1lth Annual International Meeting of the International Society for Pharmacoeconomics and Outcomes Research; May 20-24, 2006; Philadelphia, PA. Available at: http://citeseerx.ist.psu.edu/viewdoc/download ?doi=10.1.1.603.9333\&rep=repl\&type=pdf. Accessed April 14, 2018.

22. Yabroff KR, Lamont EB, Mariotto A, et al. Cost of care for elderly cancer patients in the United States. J Natl Cancer Inst. 2008;100(9):630-41.

23. Bureau of Labor Statistics. Consumer price index-all urban consumers; medical care. Available at: https://data.bls.gov/cgi-bin/surveymost. Accessed April 14, 2018.
24. Sullivan SD, Mauskopf JA, Augustovski F, et al. Budget impact analysisprinciples of good practice: report of the ISPOR 2012 Budget Impact Analysis Good Practice II Task Force. Value Health. 2014;17(1):5-14.

25. Bajaj PS, Veenstra DL, Goertz HP, Carlson JJ. Targeted erlotinib for first-line treatment of advanced non-small cell lung cancer: a budget impact analysis. J Med Econ. 2014;17(8):538-46.

26. Ramsey SD, Clarke L, Kamath TV, Lubeck D. Evaluation of erlotinib in advanced non-small cell lung cancer: impact on the budget of a U.S. health insurance plan. J Manag Care Pharm. 2006;12(6):472-78. Available at: https:// www.jmcp.org/doi/10.18553/jmcp.2006.12.6.472.

27. Carlson JJ, Garrison LP, Ramsey SD, Veenstra DL. The potential clinical and economic outcomes of pharmacogenomic approaches to EGFRtyrosine kinase inhibitor therapy in non-small-cell lung cancer. Value Health. 2009;12(1):20-27.

28. Graham J, Earnshaw S, Lim J, Luthra R, Borker R. Cost-effectiveness of afatinib versus erlotinib in the first-line treatment of patients with metastatic non-small cell lung cancer with EGFR exon 19 deletion mutations. J Clin Pathways. 2016;2(4):31-39.

29. U.S. Census Bureau, Population Division. Annual estimates of the resident population for selected age groups by sex for the United States, states, counties, and Puerto Rico Commonwealth and municipios: April 1, 2010, to July 1, 2014. 2014 population estimates. Available at: https://factfinder, census.gov/faces/tableservices/jsf/pages/productview.xhtml?pid=PEP_2017_ PEPANNRES\&src=pt. June 2015. Accessed April 14, 2018.

30. National Cancer Institute. Surveillance, Epidemiology, and End Results Program (SEER). SEER Cancer Statistics Review, 1975-2012. November 18, 2015. Available at: http://seer.cancer.gov/csr/1975_2012/. Accessed April 14, 2018.

31. National Cancer Data Base-Commission on Cancer. Histology of lung, bronchus non-small cell carcinoma cancer diagnosed in 2013. Available at: http://oliver.facs.org/BMPub/index.cfm. Accessed April 14, 2018.

32. Spicer J, Tischer B, Peters M. EGFR mutation testing and oncologist treatment choice in advanced NSCLC: global trends and differences. Poster presented at: European Lung Cancer 2015 Conference; April 15-18, 2015; Geneva, Switzerland. Available at: https://academic.oup.com/annonc/article/26/suppl_1/i60/208102. Accessed April 14, 2018.

33. Bauml J, Mick R, Zhang Y, et al. Frequency of EGFR and KRAS mutations in patients with non small cell lung cancer by racial background: do disparities exist? Lung Cancer. 2013;81(3):347-53. 
Budget Impact Analysis of Afatinib for First-Line Treatment of Patients with Metastatic Non-Small Cell Lung Cancer with Epidermal Growth Factor Receptor Exon 19 Deletions or Exon 21 Substitution Mutations in a U.S. Health Plan

\section{APPENDIX A Treatment Shares Distribution for Different Analysis Scenarios}

\begin{tabular}{|c|c|c|c|c|c|}
\hline & Year 1 & Year 2 & Year 3 & Year 4 & Year 5 \\
\hline \multicolumn{6}{|c|}{ Scenario A: Constant Uptake, $\%^{a}$} \\
\hline Afatinib & 25.0 & 25.0 & 25.0 & 25.0 & 25.0 \\
\hline Erlotinib & 65.0 & 65.0 & 65.0 & 65.0 & 65.0 \\
\hline Gefitinib & 5.0 & 5.0 & 5.0 & 5.0 & 5.0 \\
\hline Pemetrexed/cisplatin & 5.0 & 5.0 & 5.0 & 5.0 & 5.0 \\
\hline \multicolumn{6}{|c|}{ Scenario B: Increase in Afatinib Uptake, $\%^{a}$} \\
\hline Afatinib & 30.0 & 35.0 & 40.0 & 45.0 & 50.0 \\
\hline Erlotinib & 60.7 & 56.3 & 52.0 & 47.7 & 43.3 \\
\hline Gefitinib & 4.7 & 4.3 & 4.0 & 3.7 & 3.3 \\
\hline Pemetrexed/cisplatin & 4.7 & 4.3 & 4.0 & 3.7 & 3.3 \\
\hline \multicolumn{6}{|c|}{ Scenario B-1: Less Aggressive Uptake of Afatinib, \%a } \\
\hline Afatinib & 27.5 & 30.0 & 32.5 & 35.0 & 37.5 \\
\hline Erlotinib & 62.8 & 60.7 & 58.5 & 56.3 & 54.2 \\
\hline Gefitinib & 4.8 & 4.7 & 4.5 & 4.3 & 4.2 \\
\hline Pemetrexed/cisplatin & 4.8 & 4.7 & 4.5 & 4.3 & 4.2 \\
\hline \multicolumn{6}{|c|}{ Scenario B-2: More Aggressive Uptake of Afatinib, $\%^{a}$} \\
\hline Afatinib & 35.0 & 45.0 & 55.0 & 65.0 & 75.0 \\
\hline Erlotinib & 56.3 & 47.7 & 39.0 & 30.3 & 21.7 \\
\hline Gefitinib & 4.3 & 3.7 & 3.0 & 2.3 & 1.7 \\
\hline Pemetrexed/cisplatin & 4.3 & 3.7 & 3.0 & 2.3 & 1.7 \\
\hline \multicolumn{6}{|c|}{ Scenario B-3: Shares from Erlotinib, $\%^{a}$} \\
\hline Afatinib & 30.0 & 35.0 & 40.0 & 45.0 & 50.0 \\
\hline Erlotinib & 60.0 & 55.0 & 50.0 & 45.0 & 40.0 \\
\hline Gefitinib & 5.0 & 5.0 & 5.0 & 5.0 & 5.0 \\
\hline Pemetrexed/cisplatin & 5.0 & 5.0 & 5.0 & 5.0 & 5.0 \\
\hline
\end{tabular}


Budget Impact Analysis of Afatinib for First-Line Treatment of Patients with Metastatic Non-Small Cell Lung Cancer with Epidermal Growth Factor Receptor Exon 19 Deletions or Exon 21 Substitution Mutations in a U.S. Health Plan

APPENDIX B Derivation of Other Medical Cost for Patient Progression Free

\begin{tabular}{|c|c|c|c|c|c|}
\hline Resource & $\begin{array}{l}\text { Number Used } \\
\text { per } 3 \text { Weeks }\end{array}$ & Unit Costs, \$ & $\begin{array}{l}\text { Cost per } 3 \\
\text { Weeks, } \$\end{array}$ & $\begin{array}{l}\text { Cost per } \\
\text { Month, } \$^{b}\end{array}$ & $\begin{array}{l}\text { Sources and Assumptions } \\
\text { of Unit Costs }\end{array}$ \\
\hline \multicolumn{6}{|l|}{ Outpatient visits } \\
\hline General practitioner & 0.0326 & 80.11 & 2.61 & 3.79 & Essential RBRVS (CPT-4 99213)16 \\
\hline Specialist & 0.1019 & 158.67 & 16.17 & 23.43 & Essential RBRVS (CPT-4 99215)6 \\
\hline Nurse & 0.0893 & 22.17 & 1.98 & 2.87 & Essential RBRVS (CPT-4 99211)16 \\
\hline Physiotherapist & 0.0016 & 22.17 & 0.04 & 0.05 & \\
\hline \multicolumn{6}{|l|}{ Outpatient interventions } \\
\hline Computed tomography scan & 0.0226 & 329.78 & 7.45 & 10.80 & Essential RBRVS (CPT-4 71275)16 \\
\hline Magnetic resonance imaging & 0.0071 & 437.11 & 3.10 & 4.50 & Essential RBRVS (CPT-4 71555)16 \\
\hline Respiratory surgical procedure & 0.0054 & 495.44 & 2.68 & 3.88 & Essential RBRVS (CPT-4 32405, 76942)16 \\
\hline Ultrasound & 0.0056 & 97.61 & 0.55 & 0.79 & Essential RBRVS (CPT-4 76604)16 \\
\hline X-ray & 0.0280 & 30.72 & 0.86 & 1.25 & Essential RBRVS (CPT-4 71020)16 \\
\hline Radiotherapy & 0.0021 & 378.00 & 0.79 & 1.15 & Essential RBRVS (CPT-4 77385)16 \\
\hline \multicolumn{6}{|l|}{ Unplanned hospitalizations } \\
\hline Unscheduled hospitalization stay & 0.0495 & $19,176.71$ & 949.25 & $1,375.84$ & ICD-9-CM 162.0-162.9c,19 \\
\hline Intensive care unit visit & 0.0238 & $3,525.44$ & 83.91 & 121.61 & Candrilli and Mauskopfc,21 \\
\hline Emergency department visit & 0.0383 & $1,678.82$ & 64.30 & 93.20 & Medical Expenditure Panel Survey ${ }^{c, 20}$ \\
\hline Total base cost estimated for Medicare, $\$$ & & & & $1,643.16$ & \\
\hline Commercial costs estimated as $20 \%$ higher, $\$$ & & & & $1,971.79$ & \\
\hline $95 \% \mathrm{CI}, \$$ & & & & $33-2,927.15$ & \\
\hline \multicolumn{6}{|c|}{$\begin{array}{l}\text { aResource utilization information was collected from the LUX-Lung } 3 \text { trial (data on file, Boehringer Ingelheim, Health economic report: final, November 23, 201 } \\
\text { bEach number presented has been rounded to the decimal place presented. Totals are rounded after using unrounded numbers, so totals as presented may not su } \\
\text { to their parts. } \\
\text { 'Costs were inflated to } 2017 \text { dollars using the medical care component of the Consumer Price Index. }{ }^{23} \\
C I=\text { confidence interval; CPT-4 =Current Procedural Terminology, 4th Edition; ICD-9-CM = International Classification of Diseases, Ninth Revision, Clinical } \\
\text { Modification; RBRVS = Resource-Based Relative Value Scale. }\end{array}$} \\
\hline
\end{tabular}

